\title{
Effect of propofol and etomidate on normoxic and chronically hypoxic pulmonary artery
}

\author{
Nazinigouba Ouédraogo ${ }^{1,2}$, Boutchi Mounkaïla ${ }^{1}$, Huguette Crevel ${ }^{1}$, \\ Roger Marthan ${ }^{1}$ and Etienne Roux*1
}

\begin{abstract}
Address: ${ }^{1}$ Laboratoire de Physiologie Cellulaire Respiratoire, Université Bordeaux 2, Bordeaux, F-33076 France; Inserm, E356, Bordeaux, F-33076, France and ${ }^{2}$ UFR/SDS Université de Ouagadougou, Burkina Faso, France

Email: Nazinigouba Ouédraogo - nazinigouba@cenatrin.bf; Boutchi Mounkaïla - m_boutchi@yahoo.fr; Huguette Crevel - huguette.crevel@ubordeaux2.fr; Roger Marthan - roger.marthan@u-bordeaux2.fr; Etienne Roux* - etienne.roux@u-bordeaux2.fr

* Corresponding author
\end{abstract}

Published: 03 March 2006

BMC Anesthesiology2006, 6:2 doi:10.1/86/147/-2253-6-2
Received: 18 October 2005

Accepted: 03 March 2006

This article is available from: http://www.biomedcentral.com/I47I-2253/6/2

(c) 2006Ouédraogo et al; licensee BioMed Central Ltd.

This is an Open Access article distributed under the terms of the Creative Commons Attribution License (http://creativecommons.org/licenses/by/2.0), which permits unrestricted use, distribution, and reproduction in any medium, provided the original work is properly cited.

\begin{abstract}
Background: Chronic alveolar hypoxia results in sustained arterial constriction, and increase in pulmonary vascular resistance leading to pulmonary artery hypertension (PAHT). The aim of this study was to investigate the effect of propofol and etomidate on pulmonary artery (PA) reactivity in chronically hypoxic $(\mathrm{CH})$ rats, a model of pulmonary arterial hypertension (PAHT), in normoxic animals, and human PA.
\end{abstract}

Methods: $\mathrm{CH}$ rats were maintained 14 days at $380 \mathrm{mmHg}$ pressure in a hypobaric chamber. Human tissue was retrieved from histological lung pieces from patients undergoing resection for carcinoma. Cumulative concentrations of anaesthetics were tested on isolated vascular rings precontracted with phenylephrine $(\mathrm{PHE})$ or $100 \mathrm{mM} \mathrm{KCl}$. Statistical comparisons were done by ANOVA, followed, when needed, by Student $t$ tests with Bonferroni correction as post-hoc tests.

Results: In normoxic rat PA, maximal relaxation $\left(R_{\max }\right)$ induced by etomidate and propofol was $101.3 \pm 0.8 \%$ and $94.0 \pm 2.3 \%$, respectively, in $\mathrm{KCl}$-precontracted rings, and $63.3 \pm 9.7 \%$ and 46.1 $\pm 9.1 \%$, respectively, in PHE-precontracted rings $(n=7)$. In $\mathrm{KCl}$-precontracted human $\mathrm{PA}, \mathrm{R}_{\max }$ was $84.7 \pm 8.6 \%$ and $66.5 \pm 11.8 \%$, for etomidate and propofol, respectively, and $154.2 \pm 22.4 \%$ and $51.6 \pm 15.1 \%$, respectively, in PHE-precontracted human PA $(n=7)$. In $\mathrm{CH}$ rat PA, the relaxant effect of both anaesthetics was increased in PHE-precontracted and, for etomidate only, in $\mathrm{KCl}$ precontracted PA. In aorta, $\mathrm{CH}$ induced no change in the relaxant effect of anaesthetics.

Conclusion: Propofol and etomidate have relaxant properties in PA from human and normoxic rat. The relaxant effect is specifically accentuated in PA from $\mathrm{CH}$ rat, mainly via an effect on the pharmacomechanical coupling. Etomidate appears to be more efficient than propofol at identical concentration, but, taking into account clinical concentrations, etomidate is less potent than propofol, which effect was in the range of clinical doses. Although these findings provide experimental support for the preferential use of etomidate for haemodynamic stability in patients suffering from PAHT, the clinical relevance of the observations requires further investigation. 


\section{Background}

Chronic hypoxia $(\mathrm{CH})$ occurs in people living at high altitude and in children who suffer congenital heart disease with left to right shunt; it is also a main characteristic of chronic obstructive pulmonary disease, a major cause of death that affects a significant proportion of adults. Chronic alveolar hypoxia results in sustained arterial constriction, an increase in pulmonary vascular resistance leading to pulmonary artery hypertension (PAHT). At last, PAHT is responsible for right ventricular failure, which may end in death $[1,2]$. Patients with PAHT may undergo anaesthesia, i. e., for cardiac surgery or heart catheterisation. During general anaesthesia of such patients, variations in cardiac and pulmonary flows may lead to dangerous increase or decrease of systemic or pulmonary pressures. Such variations during catheterism would make the procedure useless. It is then important to consider the effects of the anaesthetics on vascular responsiveness.

The effect of etomidate on vascular reactivity has been poorly investigated. Early clinical studies showed that anaesthesia with etomidate induces little or no change in both pulmonary and systemic arterial pressure $[3,4]$. Murday et al. [5] had observed an increase in pulmonary vascular resistance and a decrease in systemic vascular resistance in patients undergoing cardiac surgery, whereas Shapiro et al evidenced a decrease in mean arterial pressure [6]. In experimental studies, etomidate has been shown to inhibit relaxant responses in canine pulmonary arteries [7]. Experiments on isolated rat lung indicated that etomidate is a direct pulmonary vasoconstrictor [8]. The effect of etomidate on systemic and pulmonary vasculature remains hence unclear.

Propofol has become a widely used general anaesthetic during the last decade and was studied in many clinical trials. However, its effect on pulmonary vasculature is unclear. In some clinical trial, propofol altered neither pulmonary mean arterial pressure nor pulmonary vascular resistance, though it decreased systemic vascular resistance [9], whereas in other studies it was shown to decrease both pulmonary arterial pressure and pulmonary arterial resistance [10]. Experimental studies on rats isolated lungs showed a direct vasodilatant effect of propofol [8], and a relaxant effect was also evidenced on rat isolated pulmonary arterial rings $[11,12]$. By contrast, it has been shown in dogs and canine isolated pulmonary arterial rings that propofol potentiates phenylephrine-induced vasoconstriction $[13,14]$. As for etomidate, the effect of propofol on pulmonary artery remains hence highly controversial.

Most of the experimental studies have been performed on normal arteries. However, PAHT is associated with morphological and functional changes of pulmonary artery, mainly hypertrophy and hyperplasia of smooth muscle cells, and altered vascular reactivity and $\mathrm{Ca}^{2+}$ homeostasis $[15,16]$. These functional and morphological alterations have been noted both in small intralobar PA and in main PA, indicating that main PA can be used as a relevant model for the study of pulmonary vasomotricity in $\mathrm{CH}$ conditions [17-22]. We have hence assessed the effects of propofol and etomidate on main pulmonary artery reactivity of chronically hypoxic $(\mathrm{CH})$ rats, a model of PAHT, versus normoxic rat and human isolated pulmonary arteries. Since chronic hypoxia has differential effects on the systemic versus the pulmonary vasculature, we compared the results obtained in rat pulmonary artery with those obtained in systemic thoracic vasculature, i. e., thoracic aorta, in order to determine if the changes in the effect of anaesthetics observed in pulmonary artery were specific.

\section{Methods \\ Chronic hypoxia protocol}

The animals used in this study were treated and sacrificed in accordance with national guidelines, and the protocol accepted by local animal experimentation committee. Male Wistar rats, 8-10 weeks old, were exposed to a simulated altitude of $5500 \mathrm{~m}$ (barometric pressure 380 $\mathrm{mmHg}$ ) in a well-ventilated, temperature-controlled hypobaric chamber for 14 days, as previously described $[23,24]$. Such a protocol is classically used to generate PAHT $[18,19,25,26]$. In previous studies, our laboratory has characterized this model of hypobaric hypoxiainduced PAHT and shown that this protocol consistently increases mean pulmonary arterial pressure, vessel wall thickness and produces right ventricular hypertrophy evidenced by an increase in the ratio of right ventricle to left ventricle + septum weight (RV/LVS) [15,23,27-30]. Normoxic rats were kept under similar conditions but not in the hypobaric chamber.

\section{Tissue preparation}

Rat pulmonary arteries and aorta from normoxic and hypoxic animals were obtained as follows: for each experiment, a rat was killed by cervical dislocation. The heart and lungs were removed en-bloc, and the extrapulmonary artery and the thoracic part of the aorta were rapidly dissected out. From each specimen, 3 rings 3-4 $\mathrm{mm}$ in length were obtained from the main, left and right extrapulmonary artery, and 3 rings of similar length from the thoracic portion of the aorta.

Human bronchial rings were obtained from lung pieces collected for histological examination following resection for carcinoma. Specimens were selected from 7 patients for whom no sign of pulmonary hypertension appeared after pulmonary radiology and clinical examination. Patients were $60.6 \pm 4.1$ years old. Their lung function was within the normal range: mean forced expiratory volume 
A

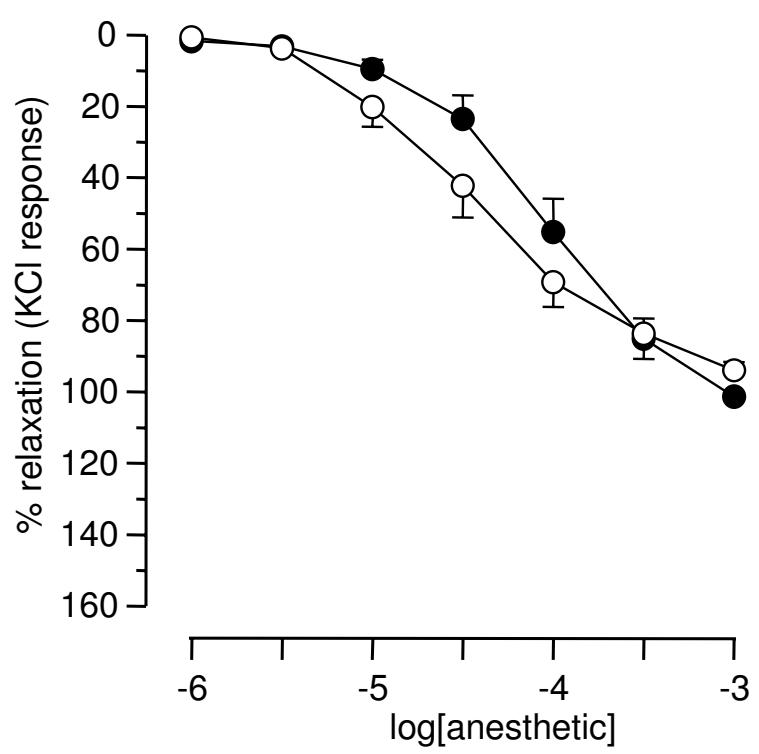

B

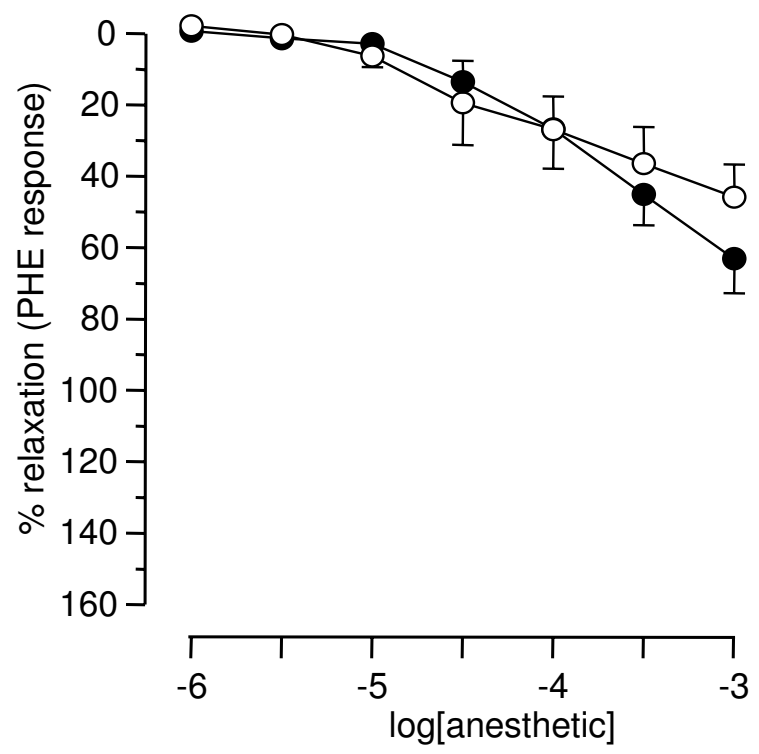

Ouedraogo et al, figure 1

\section{Figure I}

Relaxant effect of etomidate and propofol on normoxic rat pulmonary arterial rings. Abscissa: log concentration of anaesthetics (M). Ordinate: isometric contraction (\% of the paired temporal control unexposed rings). Full circles: rings exposed to etomidate. Open circles: rings exposed to propofol. A: rings precontracted with 100 $\mathrm{mM} \mathrm{KCl}$. B: rings precontracted with $10^{-6} \mathrm{M}$ PHE. Each symbol is mean value from 5 to 8 rats. Vertical bars are SEM. $P>$ 0.05 (overall comparison of etomidate versus propofol).

in 1 second $\left(\mathrm{FEV}_{1}\right)$ was $84.4 \pm 6.4 \%$ of predicted values and mean partial $\mathrm{O}_{2}$ pressure was $83.7 \pm 3.3 \mathrm{~mm} \mathrm{Hg}$.
Quickly after resection, segments of pulmonary arteries ( $3^{\text {rd }}$ to $5^{\text {th }}$ generation; $3-5 \mathrm{~mm}$ in internal diameter) were carefully dissected from a macroscopically tumour-free part of each of the histological pieces and transferred to the laboratory in an ice-cold physiological saline solution. Segments were then cut into rings measuring about 4-5 $\mathrm{mm}$ in length for isometric contraction measurements. Use of human tissues was performed according to national guidelines, in compliance with the Helsinki Declaration. Since tissues were obtained incidentally to patient surgery and discarded by the histological pathologist, specific ethical approval of the protocol was not required by French laws.

\section{Isometric tension measurement}

Isometric tension was measured in intact, i. e., with endothelium, vessel rings that were mounted between two stainless steel clips in vertical $20 \mathrm{ml}$ organ baths of a computerized isolated organ bath system (IOX, EMKA Technologies, Paris, France) previously described $[15,24]$. Baths were filled with Krebs-Henseleit (KH) solution (composition given below) maintained at $37^{\circ} \mathrm{C}$ and bubbled with a $95 \% \mathrm{O}_{2}-5 \% \mathrm{CO}_{2}$ gas mixture. The upper stainless clip was connected to an isometric force transducer (EMKA Technologies). Tissues were set at optimal length (Lo) by equilibration against a passive load of $1.5 \mathrm{~g}$ in rat aorta, normoxic human and rat pulmonary arteries, and $2.5 \mathrm{~g}$ in $\mathrm{CH}$ rat pulmonary arteries, as determined for these types of preparation in control experiments (data not shown).

The relaxant effect of cumulative concentrations of etomidate and propofol on precontraction to phenylephrine and $\mathrm{KCl}$ was assessed as follows. At the beginning of each experiment, prior to exposure to anaesthetics, a contraction was elicited by either a hyperpotassic extracellular solution containing $100 \mathrm{mM} \mathrm{KCl}$ or $10^{-6} \mathrm{M}$ phenylephrine (PHE). According to the Nernst equation, $100 \mathrm{mM} \mathrm{KCl}$ depolarises the membrane potential close to $-10 \mathrm{mV}$, which opens the voltage-operated $\mathrm{Ca}^{2+}$ channels and thus activates the electromechanical coupling. PHE is an $\alpha_{1^{-}}$ adrenergic agonist that binds to $\mathrm{G}$ protein-coupled receptor and acts mainly via $\mathrm{InsP}_{3}$ production and $\mathrm{Ca}^{2+}$ release from intracellular stores, the so-called pharmacomechanical coupling. $10^{-6} \mathrm{M}$ PHE induces an inframaximal contractile response, as determined from a cumulativeconcentration response curve to PHE in rat aorta and pulmonary artery ( $\mathrm{n}=4$, data not shown). Upon $\mathrm{KCl}$ or PHE administration, when the maximal contraction was obtained, propofol or etomidate was added to the vessel rings in cumulative half-log increments from $10^{-6}$ to $10^{-3}$ $\mathrm{M}$. The ring tension was measured when the response stabilized, i.e., after an equilibration time about $15 \mathrm{~min}$, and expressed as a percentage of the maximal initial contraction of that ring. To avoid any bias due to time-dependent 
change in tension, the anaesthetic-induced relaxation was normalized to a paired temporal ring, i.e., a ring experimented simultaneously in similar conditions but without exposure to the anaesthetics.

\section{Chemicals and drugs}

PHE were purchased from Sigma (Saint Quentin Fallavier, France). Propofol (Diprivan ${ }^{\circledR}$, Zeneca laboratories, Cergy France) and etomidate (Hypnomidate ${ }^{\circledast}$, Janssen laboratories, Boulogne Billancourt, France) were obtained from their clinically used presentations. We verified that the vehicle of each of the drugs had no effect per se on contractile responses up to the maximal concentration used in the present experiments, i. e., 1.65\%. Normal KH solution contained (in $\mathrm{mM}$ ): $118.4 \mathrm{NaCl}, 4.7 \mathrm{KCl}, 2.5$ $\mathrm{CaCl}_{2} .2 \mathrm{H}_{2} \mathrm{O}, \quad 1.2 \mathrm{MgSO}_{4} .7 \mathrm{H}_{2} \mathrm{O}, 1.2 \mathrm{KH}_{2} \mathrm{PO}_{4}, 25.0$ $\mathrm{NaHCO}_{3}, 11.1$ D-glucose, $\mathrm{pH}$ 7.4. For KCl-induced contraction, $\mathrm{KCl}$ was substituted to $\mathrm{NaCl}$ for the desired concentrations, in order to keep the osmotic pressure constant.

\section{Analysis of results and statistics}

The relaxation induced by each concentration of anaesthetic was expressed as a percentage of the contractile response of the paired temporal control. The concentration-dependent relaxation curves were then fitted by a non-linear Boltzman equation used to determine the concentrations of anaesthetics that reduced the maximal contraction by $50 \%\left(\mathrm{IC}_{50}\right)$ and by $30 \%\left(\mathrm{IC}_{30}\right)$, reported as negative logarithm ( $\mathrm{pIC}_{50}$ and $\mathrm{pIC}_{30}$, respectively), according to Lovren and Triggle [31], and as we previously used in airways [24]. $\mathrm{R}_{\max }$ refers to the maximal relaxation obtained at the maximal anaesthetic concentration $\left(10^{-3}\right.$ M).

Each experimental condition was repeated on 6 to 9 different specimens. Data are given as mean \pm SEM. Overall cumulative concentration-response curves in control, etomidate- and propofol-exposed rings were compared using ANOVA for repeated measurements. Comparison of $\mathrm{pIC}_{30}, \mathrm{pIC}_{50}$ and $\mathrm{R}_{\max }$ was done by ANOVA, followed, when needed, by Student $t$ tests with Bonferroni correction as post-hoc tests. Statistical tests were performed using the SPSS ${ }^{\circledast}$ statistical software. Differences were considered significant when $P<0.05$.

\section{Results}

\section{Effect of etomidate and propofol on normoxic rat pulmonary arterial rings}

Both etomidate and propofol significantly relaxed precontracted PA rings (figure 1). Overall comparison of the curves showed no difference in the effect of propofol versus etomidate in $\mathrm{KCl}$ - as well as in PHE-precontracted rings. The relaxant effect of both compounds was greater on KCl-precontracted $\mathrm{PA}$ rings, since $\mathrm{pIC}_{30}, \mathrm{pIC}_{50}$ and
$\mathrm{R}_{\text {max }}$ were significantly greater in $\mathrm{KCl}$ - than PHE-precontracted tissues (tables 1 and 2).

\section{Effect of etomidate and propofol on human pulmonary artery rings}

Overall comparison of the curves showed that propofol and etomidate had a similar concentration-dependent relaxant effect, as shown in fig. 2, despite an apparent greater effect for the highest concentration of etomidate in PHE-precontracted rings. Comparison of human versus normoxic rat PA showed that, for both anaesthetics, $\mathrm{R}_{\max }$ was similar or higher in human PA. However, in KCl-precontracted rings, $\mathrm{pIC}_{30}$ and $\mathrm{pIC}_{50}$ were higher in rat PA (tables 1 and 2).

\section{Effect of etomidate and propofol on $\mathrm{CH}$ rat pulmonary arterial rings}

Both etomidate and propofol significantly relaxed precontracted PA rings from chronically hypoxic rats (figure 3). Overall comparison of the curves showed no difference in the effect of propofol versus etomidate in KCl-precontracted rings, whereas etomidate was more potent than propofol in PHE-precontracted PA rings. In contrast with observations on normoxic PA, no significant difference was observed in $\mathrm{R}_{\max }$ and $\mathrm{pIC}_{30}$ between $\mathrm{KCl}$ - and PHEprecontracted tissues (tables 1 and 2). Comparison between results obtained in PA from normoxic and $\mathrm{CH}$ rats showed that in PHE-precontracted rings, $\mathrm{R}_{\text {max }}, \mathrm{pIC}_{30}$ and $\mathrm{pIC}_{50}$ were higher in $\mathrm{CH}$ tissues. In $\mathrm{KCl}$-precontracted rings, though $\mathrm{R}_{\max }$ was greater in $\mathrm{CH}$ rings for both anaesthetics, the difference was significant only for etomidate, and no change was observed for $\mathrm{pIC}_{30}$ and $\mathrm{pIC}_{50}$ (tables 1 and 2).

\section{Effect of etomidate and propofol on normoxic and $\mathrm{CH}$ rat thoracic aorta}

In rings from normoxic rats, both propofol and etomidate had a significant relaxant effect on $\mathrm{KCl}$-and $\mathrm{PHE}$-precontracted aortic rings (figure 4). Overall comparison of the curves indicated that etomidate and propofol had a similar effect on $\mathrm{KCl}$-precontracted aorta, but that etomidate was more potent than propofol in PHE-precontracted tissues. Comparisons of $\mathrm{R}_{\max }$ and $\mathrm{pIC}_{30}$ and $\mathrm{pIC}_{50}$ showed that the relaxant effect of propofol, but not of etomidate, was greater on $\mathrm{KCl}$-precontracted rings (tables 1 and 2). In rings from $\mathrm{CH}$ rats, both propofol and etomidate had also a significant relaxant effect on $\mathrm{KCl}$-and PHE-precontracted rings. Overall comparison of CCRC indicated that etomidate and propofol had a similar effect, whatever the contractant agonist. Comparison of $\mathrm{R}_{\text {max }}, \mathrm{pIC}_{30}$ and $\mathrm{pIC}_{50}$ between normoxic and $\mathrm{CH}$ aorta showed that the only difference observed was an increase in the maximal relaxation to propofol in PHE-precontracted $\mathrm{CH}$ aorta (tables 1 and 2). 
Table I: $\mathrm{R}_{\max }, \mathrm{plC}_{30}$ and $\mathrm{pIC}_{50}$ of etomidate on rat pulmonary and aorta and on human pulmonary artery precontracted by $\mathrm{KCl}$ and PHE

\begin{tabular}{|c|c|c|c|c|c|}
\hline & & $\mathrm{R}_{\max }(\%$ control $)$ & $\mathrm{plC}_{30}(\mathrm{M})$ & $\mathrm{plC}_{50}(\mathrm{M})$ & $n$ \\
\hline \multirow[t]{2}{*}{ normoxic rat $P A$} & $\mathrm{KCl}$ & $101.3 \pm 0.8^{*} \dagger$ & $4.32 \pm 0.12 * \ddagger$ & $4.06 \pm 0.13^{*} \ddagger$ & 7 \\
\hline & $\mathrm{PHE}$ & $63.3 \pm 9.7 \dagger \ddagger^{\circ}$ & $3.78 \pm 0.19 \dagger$ & $3.03 \pm 0.44 \dagger^{\dagger}$ & 7 \\
\hline \multirow[t]{2}{*}{ human PA } & $\mathrm{KCl}$ & $84.7 \pm 8.6^{*}$ & $3.74 \pm 0.12 \ddagger$ & $3.46 \pm 0.12$ & 7 \\
\hline & PHE & $154.2 \pm 22.4$ & $3.64 \pm 0.16$ & $3.48 \pm 0.14$ & 7 \\
\hline \multirow[t]{2}{*}{$\mathrm{CH}$ rat $\mathrm{PA}$} & $\mathrm{KCl}$ & $150.0 \pm 22.4$ & $4.59 \pm 0.11$ & $4.34 \pm 0.10$ & 9 \\
\hline & PHE & $149.5 \pm 19.0$ & $4.55 \pm 0.19$ & $4.32 \pm 0.19$ & 6 \\
\hline \multirow[t]{2}{*}{ normoxic rat aorta } & $\mathrm{KCl}$ & $107.0 \pm 3.1$ & $4.16 \pm 0.10$ & $3.87 \pm 0.09 \dagger$ & 9 \\
\hline & PHE & $107.0 \pm 1.6$ & $4.12 \pm 0.14$ & $3.79 \pm 0.09 \dagger$ & 7 \\
\hline \multirow[t]{2}{*}{$\mathrm{CH}$ rat aorta } & $\mathrm{KCl}$ & $112.2 \pm 6.6$ & $4.38 \pm 0.04$ & $4.11 \pm 0.06$ & 8 \\
\hline & PHE & $132.7 \pm 28.7$ & $4.54 \pm 0.16$ & $4.23 \pm 0.17$ & 6 \\
\hline
\end{tabular}

Mean maximal relaxation to etomidate $\left(\mathrm{R}_{\max }, \%\right.$ control), and mean $50 \%$ and $30 \%$ maximal contraction inhibitory concentrations (pIC ${ }_{50}$ and $\mathrm{plC}$, $\mathrm{M})$ in pulmonary artery (PA) and aorta from normoxic and chronically hypoxic $(\mathrm{CH})$ rat and in human pulmonary artery precontracted with 80 mM $\mathrm{KCl}(\mathrm{KCl})$ and $10^{-6} \mathrm{M}$ phenylephrine $(\mathrm{PHE}) . \mathrm{R}_{\max }, \mathrm{PIC}_{50}$ and $\mathrm{PlC}_{30}$ values are mean $\pm \mathrm{SEM}$. $* \mathrm{P}<0.05 \mathrm{KCl}$ versus $\mathrm{PHE} ; \mathrm{P}<0.05$ normoxic versus $\mathrm{HC}$ tissues; $\ddagger P<0.05$ rat PA versus Human PA; ${ }^{\circ} P<0.05$ PA versus aorta.

\section{Discussion}

Our results show that propofol and etomidate display a concentration-dependent relaxant effect on pulmonary vasculature. The effect of propofol on PA observed in this study is in accordance with several experimental data that have shown a relaxant effect of propofol on PA $[8,11,12]$ However, some studies have evidenced a contractant effect of propofol on PA [13,14,32,33]. The discrepancy with our study may be due to species differences, since these studies, showing a contractant effect of propofol on $\mathrm{PA}$, were performed in dogs or on canine isolated tissues, whereas we evidenced a relaxant effect of propofol in both rat and human PA. In pulmonary artery, etomidate appeared to have a similar or even greater relaxant effect than propofol. Again, this result is in disagreement with previous studies that have evidenced an antirelaxant effect of etomidate in canine pulmonary artery [34]. In addition to species or tissues differences, it should also be noticed that in these studies the experimental conditions differed from ours and focused on the possible effect of etomidate on relaxant agents, not contractant ones.

Comparison of the $\mathrm{R}_{\max }$ obtained in rat versus human pulmonary arteries indicates that both anaesthetics have similar or even greater maximal relaxant effect in human compared to rat tissues. However, it should be noticed that for etomidate as well as propofol, $\mathrm{pIC}_{30}$ and $\mathrm{pIC}_{50}$ were higher in rat than in human PA precontracted with $\mathrm{KCl}$. This indicates that, though both anaesthetics have a relaxant effect on PA from both species, human PA is less sensitive than rat one to the effect of propofol and etomidate, suggesting small, if any, relaxant effect of etomidate and propofol on normoxic human pulmonary artery at clinical concentrations.

For the two anaesthetics tested, the relaxant effect was greater in $\mathrm{CH}$ versus normoxic tissues. Though experiments, for obvious ethical considerations, have not been

Table 2: $\mathbf{R}_{\max }, \mathrm{PIC}_{30}$ and $\mathrm{pIC}_{50}$ of propofol on rat pulmonary and aorta and on human pulmonary artery precontracted by $\mathrm{KCl}$ and $\mathrm{PHE}$

\begin{tabular}{|c|c|c|c|c|c|}
\hline & & $\mathrm{R}_{\max }(\%$ control $)$ & $\mathrm{plC}_{30}(\mathrm{M})$ & $\mathrm{plC}_{50}(\mathrm{M})$ & $\mathrm{n}$ \\
\hline \multirow[t]{2}{*}{ normoxic rat $P A$} & $\mathrm{KCl}$ & $94.0 \pm 2.3^{* \circ}$ & $4.69 \pm 0.14^{*} \ddagger^{\circ}$ & $4.35 \pm 0.14 \ddagger^{\circ}$ & 7 \\
\hline & PHE & $46.1 \pm 9.1 \dagger$ & $3.54 \pm 0.26 \dagger$ & $1.96 \pm 0.76 \dagger$ & 7 \\
\hline \multirow[t]{2}{*}{ human PA } & $\mathrm{KCl}$ & $66.5 \pm 11.8$ & $3.69 \pm 0.16 \ddagger$ & $3.01 \pm 0.30 \neq$ & 7 \\
\hline & PHE & $51.6 \pm 15.0$ & $3.33 \pm 0.34$ & $3.00 \pm 0.49$ & 7 \\
\hline \multirow[t]{2}{*}{$\mathrm{CH}$ rat $\mathrm{PA}$} & $\mathrm{KCl}$ & $127.4 \pm 15.9$ & $4.83 \pm 0.17$ & $4.49 \pm 0.17$ & 9 \\
\hline & PHE & $90.1 \pm 11.7$ & $4.30 \pm 0.17$ & $3.86 \pm 0.23$ & 6 \\
\hline \multirow[t]{2}{*}{ normoxic rat aorta } & $\mathrm{KCl}$ & $79.9 \pm 5.3^{*}$ & $4.32 \pm 0.10^{*}$ & $3.89 \pm 0.14^{*}$ & 9 \\
\hline & PHE & $48.1 \pm 5.3 \dagger$ & $3.53 \pm 0.14$ & $2.69 \pm 0.38$ & 7 \\
\hline \multirow[t]{2}{*}{$\mathrm{CH}$ rat aorta } & $\mathrm{KCl}$ & $101.3 \pm 16.7$ & $4.45 \pm 0.10$ & $4.15 \pm 0.11$ & 8 \\
\hline & PHE & $73.1 \pm 5.0$ & $4.09 \pm 0.24$ & $3.61 \pm 0.20$ & 6 \\
\hline
\end{tabular}

Mean maximal relaxation to propofol $\left(\mathrm{R}_{\max }, \%\right.$ control), and mean $50 \%$ and $30 \%$ maximal contraction inhibitory concentrations ( $\mathrm{PIC}$ and $\mathrm{plC}$, $\mathrm{M}$ ) in pulmonary artery (PA) and aorta from normoxic and chronically hypoxic $(\mathrm{CH})$ rat and in human pulmonary artery precontracted with 100 mM $\mathrm{KCl}(\mathrm{KCl})$ and $10^{-6} \mathrm{M}$ phenylephrine $(\mathrm{PHE})$. $\mathrm{R}_{\max }, \mathrm{plC}_{50}$ and $\mathrm{plC}_{30}$ values are mean $\pm \mathrm{SEM}$. $* \mathrm{P}<0.05 \mathrm{KCl}$ versus $\mathrm{PHE} ;+\mathrm{P}<0.05$ normoxic versus $\mathrm{HC}$ tissues; $\ddagger P<0.05$ rat $\mathrm{PA}$ versus Human $\mathrm{PA} ;{ }^{\circ} \mathrm{P}<0.05 \mathrm{PA}$ versus aorta. 
A

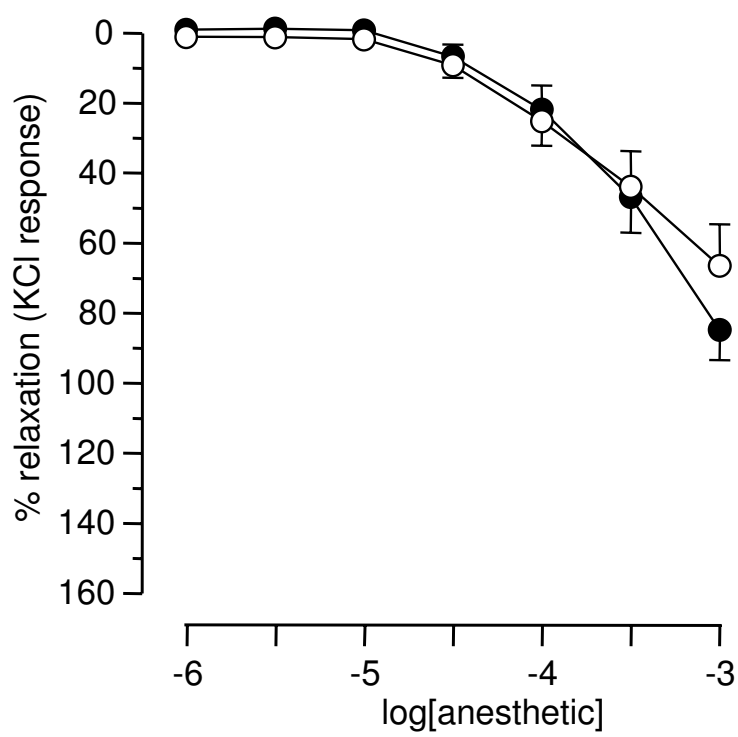

B

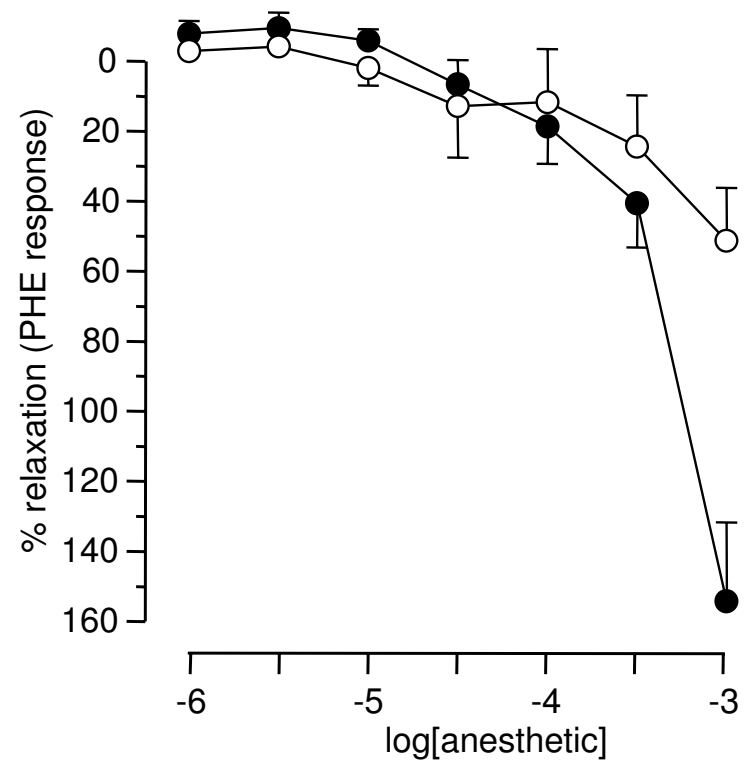

Ouedraogo et al, figure 2

Figure 2

Relaxant effect of etomidate and propofol on human pulmonary arterial rings. Abscissa: log concentration of anaesthetics (M). Ordinate: isometric contraction (\% of the paired temporal control unexposed rings). Full circles: rings exposed to etomidate. Open circles: rings exposed to propofol. A: rings precontracted with $100 \mathrm{mM} \mathrm{KCl}$. B: rings precontracted with $10^{-6} \mathrm{M}$ PHE. Each symbol is mean value from 7 specimens. Vertical bars are SEM. $P>0.05$ (overall comparison of etomidate versus propofol). performed in human tissues from $\mathrm{CH}$ hypoxic patients (CH been a usual counterindication for lung surgery), our results suggest that the effect of these anaesthetics on haemodynamics may be greater in patients suffering chronic hypoxia, especially on pulmonary haemodynamics. $\mathrm{CH}$ has different effects on systemic and pulmonary vasculature. It has been shown that hypoxia induces systemic vasorelaxation and $\mathrm{CH}$ does not induce morphological changes in systemic vasculature [35]. By contrast, hypoxia induces a specific vasoconstriction in pulmonary artery, and $\mathrm{CH}$ induces pulmonary hypertension and remodelling $[15,16,36]$. Our study showed that the enhanced relaxant effect of etomidate and propofol in tissues from $\mathrm{CH}$ animals is principally observed in pulmonary artery. This indicates that the changes in anaesthetic sensitivity are not due to chronic hypoxia per se, but specifically associated with the $\mathrm{CH}$-induced pulmonary hypertension.

The enhanced effect of the anaesthetics was mainly observed on PHE-precontracted PA. Hence, the increased sensitivity of CH PA is mainly due to an enhanced effect of the anaesthetics on the pharmacomechanical coupling. This suggests that chronic hypoxia modifies the pharmacomechanical coupling of pulmonary artery, in agreement with previous findings on $\mathrm{CH}$-induced calcium signalling in pulmonary arterial smooth muscle cells [15]. Since the pharmacomechanical coupling is activated not only by $\alpha$ adrenergic stimulation but also by several major physiological vasoactive agonists such as endothelin 1 and angiotensin 2, it is likely that propofol and etomidate may alter the physiological regulation of the pulmonary vasomotricity. Several authors have described an endothelium-dependent effect of propofol and etomidate on pulmonary vascular resistance $[32,34]$. Since our experiments were performed in rings with intact endothelium, we cannot exclude that the enhanced relaxant effect of these anaesthetics on pulmonary arteries from $\mathrm{CH}$ rats may be endothelium-mediated. However, the endothelium-dependent effect of these anaesthetics have been evidenced on ACh-induced relaxation, whereas the effect of propofol and etomidate on pulmonary arteries stimulated by contractile agonists has been shown to be endothelium-independent $[8,11,13,14,32,34]$. In particular, the effect of propofol, which was shown to be epitheliumdependent when assessed on ACh-induced relaxation [32], appeared to be epithelium-independent when tested on $\alpha$-adrenergic contraction $[11,14]$, though with opposite consequence in dogs [14] and rats [11], as mentioned above. Since the enhanced effect of both anaesthetics were mainly observed on phenylephrine-precontracted rings, it is therefore likely that this effect may be endotheliumindependent. 
A

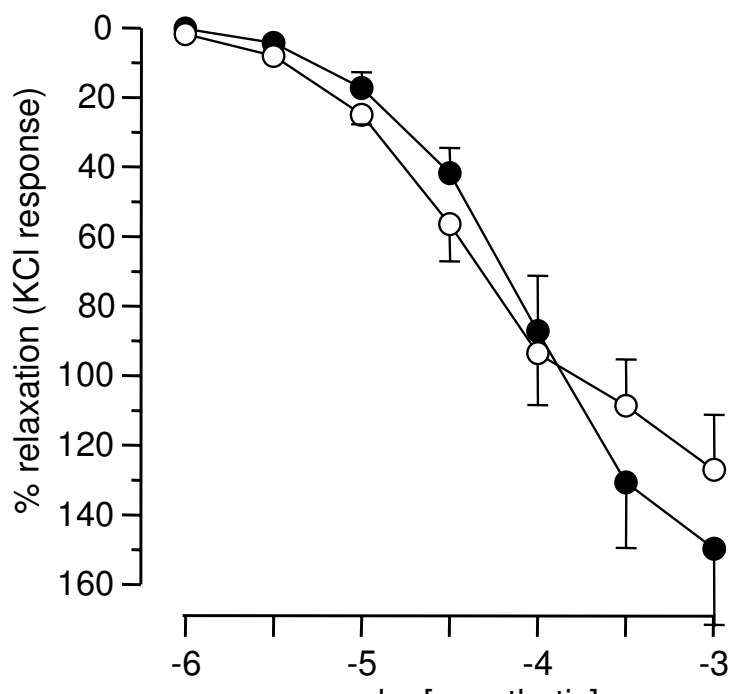

B

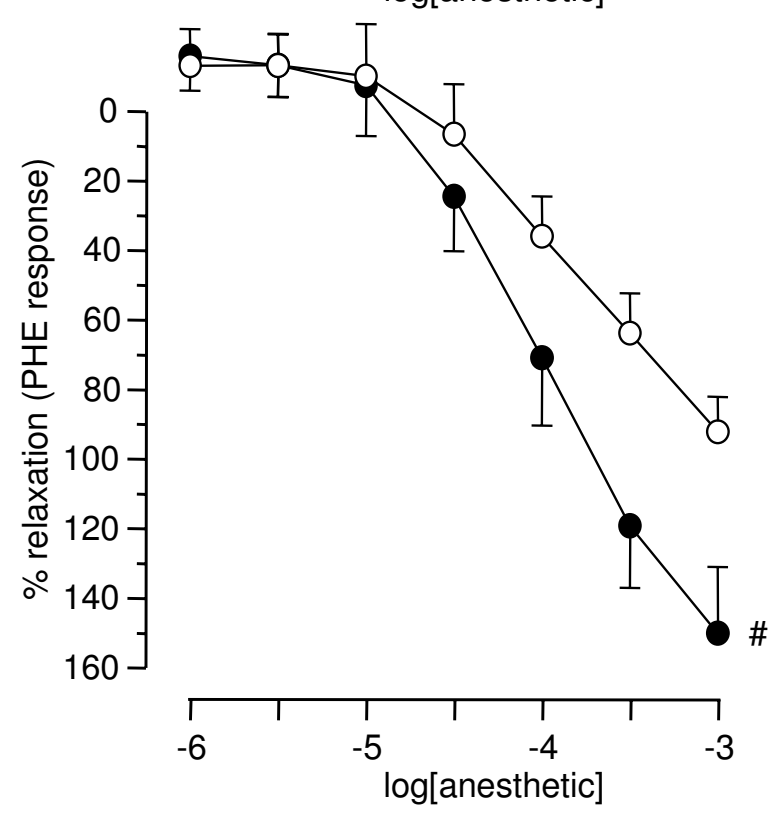

Ouedraogo et al, figure 3

Figure 3

Relaxant effect of etomidate and propofol on pulmonary arterial rings from chronically hypoxic rats. Abscissa: log concentration of anaesthetics (M). Ordinate: isometric contraction (\% of the paired temporal control unexposed rings). Full circles: rings exposed to etomidate. Open circles: rings exposed to propofol. A: rings precontracted with $100 \mathrm{KCl}$. B: rings precontracted with $10-6 \mathrm{M}$ PHE. Each symbol is mean value from 5 to 8 rats. Vertical bars are SEM. \# $P<0.05$ (overall comparison of etomidate versus propofol).
Though pulmonary artery and aorta rings used in this study were from chronically hypoxic animals, the experimental conditions for isometric measurements were not hypoxic, rather hyperoxic, since tissues were bubbled with $95 \% \mathrm{O}_{2}$ and $5 \% \mathrm{CO}_{2}$. Since anesthetized patients are usually ventilated with hyperoxic gas mixture, our experimental conditions remain, nevertheless, clinically relevant.

Blood concentrations of propofol and etomidate, following clinical injection, are about 3-15 $\mu \mathrm{g} \cdot \mathrm{mL}^{-1}$ and $0.5-1,6$ $\mu \mathrm{g} . \mathrm{mL}^{-1}$, respectively [37-41]. This corresponds to $10^{-5}-10^{-}$ ${ }^{4} \mathrm{M}$ for propofol concentration, and about $2-6.10^{-6} \mathrm{M}$ for etomidate. At these concentrations, below $\mathrm{IC}_{30}$ values, etomidate has no significant relaxant effect in normoxic tissues and, though enhanced, small effect on $\mathrm{CH}$ ones. This may explain why clinical studies have generally not concluded to a relaxant effect of etomidate on PA [5,8], and suggests a small, if any, effect of etomidate on pulmonary haemodynamics in $\mathrm{CH}$ patients. By contrast, clinical concentrations of propofol may be in the same range of $\mathrm{IC}_{30}$ values. This may explain why some authors have concluded that propofol infusion at clinical doses decreases pulmonary arterial pressure and pulmonary arterial resistances [10]. Moreover, since the relaxant effect was increased in $\mathrm{CH}$ rat pulmonary arteries, the effect of propofol on pulmonary haemodynamics may be higher in $\mathrm{CH}$ subjects. Hence, our study provides experimental support for the preferential use of etomidate for the maintenance of haemodynamic stability in patients suffering from PAHT. However, one should be cautious in extrapolating ex vivo data to in vivo conditions, in particular because of the high protein binding of these compounds which decreases their free concentrations and hence their biological effect [42].

\section{Conclusion}

In conclusion, our study demonstrates that in normoxic rats etomidate and propofol have a relaxant effect on pulmonary artery, acting mainly on the electromechanical coupling and, to a lesser degree, on the pharmacological coupling. A relaxant effect was also observed in human pulmonary artery, though human PA appears to be less sensitive to the anaesthetics than rat one. The effects of both anaesthetics were greater on PA from an animal model of hypoxia-induced pulmonary hypertension. This enhanced relaxant effect was specific to PA and was mainly seen on the pharmacomechanical coupling. Etomidate appears to be more efficient than propofol at identical concentration. However, comparison that take into account difference between etomidate and propofol concentrations used at clinical doses indicates that etomidate is less potent than propofol, which may have an effect on pulmonary haemodynamics, especially in subjects suffering $\mathrm{CH}$ and PAHT. Although these findings provide experimental support for the preferential use of etomidate in 
A
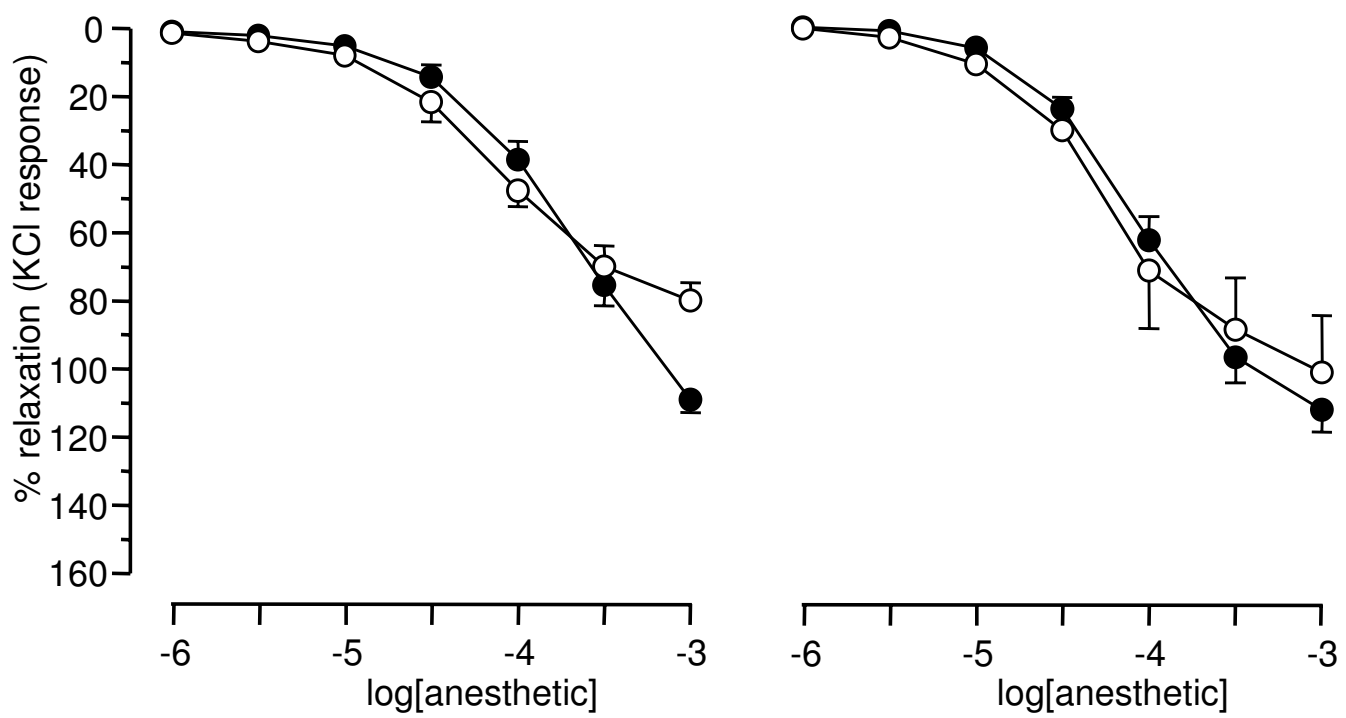

B
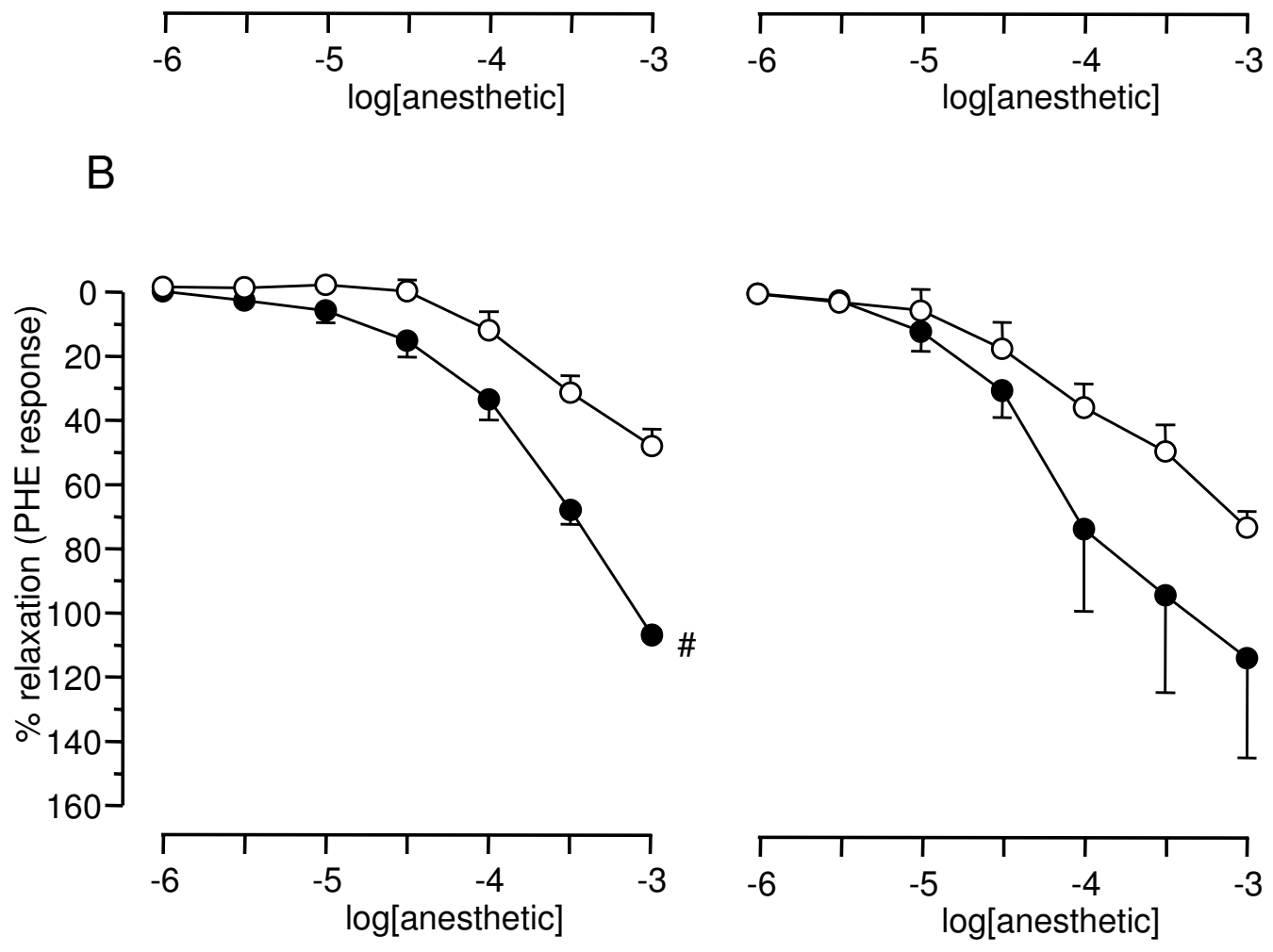
B

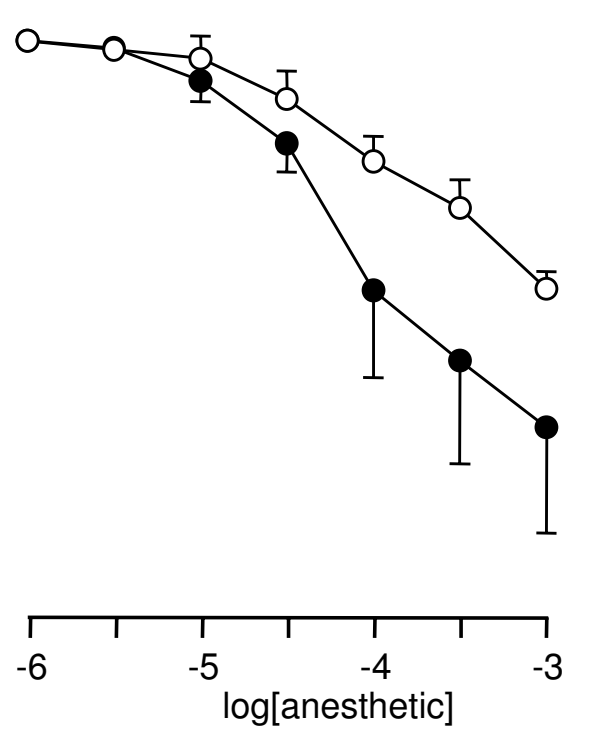

Ouedraogo et al, figure 4

\section{Figure 4}

Relaxant effect of etomidate and propofol on rat aorta rings. Left panel: aorta rings from normoxic rat. Right panel: aorta rings from $\mathrm{CH}$ rat $\mathrm{CH}$ Abscissa: log concentration of anaesthetics (M). Ordinate: isometric contraction (\% of the paired temporal control unexposed rings). Full circles: rings exposed to etomidate. Open circles: rings exposed to propofol. A: rings precontracted with $100 \mathrm{mM} \mathrm{KCl}$. B: rings precontracted with $10-6 \mathrm{M} \mathrm{PHE}$. Each symbol is mean value from 5 to 8 rats. Vertical bars are SEM. \# $P<0.05$ (overall comparison of etomidate versus propofol). 
patients suffering from PAHT, the clinical relevance of the observations requires further investigation.

\section{List of abbreviations}

CCRC: cumulative-concentration response curve

\section{HC: chronic hypoxia}

$\mathrm{IC}_{50}$ : concentration that reduces the maximal contraction by $50 \%$

$\mathrm{IC}_{30}$ : concentration that reduces the maximal contraction by $30 \%$

\section{KH: Krebs-Henseleit}

PA: pulmonary artery

PHE: phenylephrine

$\mathrm{pIC}_{50}$ : negative logarithm of $\mathrm{IC}_{50}$

$\mathrm{pIC}_{30}$ : negative logarithm of $\mathrm{IC}_{30}$

$\mathrm{R}_{\max }:$ maximal apparent relaxation

\section{Competing interests}

The author(s) declare that they have no competing interests.

\section{Authors' contributions}

NO participated in the conception of the study and its design, the experiments in rat and human tissues, participated in the analysis of the data, carried out the statistical analysis, and helped the draft of the manuscript. BM participated in the experiments in rat tissues and the analysis of data. HC participated in the contractile experiments in rat and human tissues. RM participated in the design of the study and helped the draft of the manuscript. ER participated in the conception of the study and its design, helped in statistical analysis and drafted the manuscript.

\section{Acknowledgements}

The authors thank Dr. Patrick Berger, M.D., PhD, Associate Professor of Physiology, Dr. Hughes Begueret, M.D., Ph. D. Staff Specialist of Histology, and the "Service de Chirurgie Thoracique", C.H.U. de Bordeaux, France, for the supply of human tissues, and Mr. Pierre Téchoueyres for technical assistance.

\section{References}

I. Klinger JR, Hill NS: Right ventricular dysfunction in chronic obstructive pulmonary disease. Evaluation and management. Chest 1991, 99:715-723.

2. Pierson DJ: Pathophysiology and clinical effects of chronic hypoxia. Respir Care 2000, 45:39-5I.

3. Criado A, Maseda J, Navarro E, Escarpa A, Avello F: Induction of anaesthesia with etomidate: haemodynamic study of 36 patients. Br J Anaesth 1980, 52:803-806.
4. Colvin MP, Savege TM, Newland PE, Weaver EJ, Waters AF, Brookes $J M$, Inniss R: Cardiorespiratory changes following induction of anaesthesia with etomidate in patients with cardiac disease. Br J Anaesth I979, 5 I:55 I-556.

5. Murday HK, Hack G, Hermanns E, Rudolph A: [Hemodynamic effects of an etomidate-flunitrazepam or midazolam- fentanyl combination for induction of anesthesia in patients with heart valve diseases]. Anasth Intensivther Notfallmed 1985, 20:175-I78.

6. Shapiro BM, Wendling WW, Ammaturo FJ, Chen D, Pham PS, Furukawa S, Carlsson C: Vascular effects of etomidate administered for electroencephalographic burst suppression in humans. J Neurosurg Anesthesiol 1998, 10:231-236.

7. Sohn JT, Murray PA: Inhibitory effects of etomidate and ketamine on adenosine triphosphate-sensitive potassium channel relaxation in canine pulmonary artery. Anesthesiology 2003, 98:104-I I3.

8. Rich GF, Roos CM, Anderson SM, Daugherty MO, Uncles DR: Direct effects of intravenous anesthetics on pulmonary vascular resistance in the isolated rat lung. Anesth Analg 1994, 78:961-966.

9. Williams GD, Jones TK, Hanson KA, Morray JP: The hemodynamic effects of propofol in children with congenital heart disease. Anesth Analg 1999, 89:1411-1416.

10. Hammaren E, Hynynen M: Haemodynamic effects of propofol infusion for sedation after coronary artery surgery. $\mathrm{Br} J$ Anaesth 1995, 75:47-50.

II. Park WK, Lynch C, Johns RA: Effects of propofol and thiopental in isolated rat aorta and pulmonary artery. Anesthesiology 1992, 77:956-963.

12. Tanaka H, Yamanoue T, Kuroda M, Kawamoto M, Yuge O: Propofol relaxes extrapulmonary artery but not intrapulmonary artery through nitric oxide pathway. Hiroshima J Med Sci 200I, 50:6I-64.

13. Kondo U, Kim SO, Nakayama M, Murray PA: Pulmonary vascular effects of propofol at baseline, during elevated vasomotor tone, and in response to sympathetic alpha- and betaadrenoreceptor activation. Anesthesiology 200 I, 94:8I 5-823.

14. Ogawa K, Tanaka S, Murray PA: Propofol potentiates phenylephrine-induced contraction via cyclooxygenase inhibition in pulmonary artery smooth muscle. Anesthesiology 200I, 94:833-839.

15. Bonnet S, Belus A, Hyvelin JM, Roux E, Marthan R, Savineau JP: Effect of chronic hypoxia on agonist-induced tone and calcium signaling in rat pulmonary artery. Am J Physiol Lung Cell Mol Physiol 200I, 28 I :LI93-20I.

16. Durmowicz AG, Stenmark KR: Mechanisms of structural remodeling in chronic pulmonary hypertension. Pediatr Rev 1999, 20:e91-el02.

17. Jeffery TK, Wanstall JC: Comparison of pulmonary vascular function and structure in early and established hypoxic pulmonary hypertension in rats. Can J Physiol Pharmacol 2001, 79:227-237.

18. Morecroft I, Heeley RP, Prentice HM, Kirk A, MacLean MR: 5hydroxytryptamine receptors mediating contraction in human small muscular pulmonary arteries: importance of the 5-HTIB receptor. Br J Pharmacol 1999, I 28:730-734.

19. MacLean MR, Sweeney G, Baird M, McCulloch KM, Houslay M, Morecroft I: 5-Hydroxytryptamine receptors mediating vasoconstriction in pulmonary arteries from control and pulmonary hypertensive rats. Br J Pharmacol 1996, I I 9:917-930.

20. Rondelet B, Kerbaul F, Van Beneden R, Motte S, Fesler P, Hubloue I, Remmelink M, Brimioulle S, Salmon I, Ketelslegers JM, Naeije R: Signaling molecules in overcirculation-induced pulmonary hypertension in piglets: effects of sildenafil therapy. Circulation 2004, I I 0:2220-2225.

21. Marcos E, Fadel E, Sanchez O, Humbert M, Dartevelle P, Simonneau G, Hamon M, Adnot S, Eddahibi S: Serotonin-induced smooth muscle hyperplasia in various forms of human pulmonary hypertension. Circ Res 2004, 94:1263-1270.

22. Jeffery TK, Wanstall JC: Pulmonary vascular remodelling in hypoxic rats: effects of amlodipine, alone and with perindopril. Eur J Pharmacol 2001, 416:123-131.

23. Roux E, Duvert M, Marthan R: Combined effect of chronic hypoxia an in vitro exposure to gas pollutants on airway reactivity. Am J Physiol (Lung Cell Mol Physiol) 2002, 283:L628-35. 
24. Ouedraogo N, Marthan R, Roux E: The effects of propofol and etomidate on airway contractility in chronically hypoxic rats. Anesth Analg 2003, 96:1035-104I.

25. Karamsetty MR, Klinger JR, Hill NS: Phytoestrogens restore nitric oxide-mediated relaxation in isolated pulmonary arteries from chronically hypoxic rats. I Pharmacol Exp Ther 200I, 297:968-974.

26. MacLean MR, Morecroft I: Increased contractile response to 5hydroxytryptaminel-receptor stimulation in pulmonary arteries from chronic hypoxic rats: role of pharmacological synergy. BrJ Pharmacol 200I, I34:6 |4-620.

27. Belouchi NE, Roux E, Savineau JP, Marthan R: Effect of chronic hypoxia on calcium signalling in airway smooth muscle cells. Eur Respir J 1999, 14:74-79.

28. Bonnet S, Dubuis E, Vandier C, Martin S, Marthan R, Savineau JP: Reversal of chronic hypoxia-induced alterations in pulmonary artery smooth muscle electromechanical coupling upon air breathing. Cardiovasc Res 2002, 53:1019-1028.

29. Bonnet S, Dumas-de-La-Roque E, Begueret H, Marthan R, Fayon M, Dos Santos P, Savineau JP, Baulieu EE: Dehydroepiandrosterone (DHEA) prevents and reverses chronic hypoxic pulmonary hypertension. Proc Natl Acad Sci U S A 2003, I 00:9488-9493.

30. Pauvert O, Bonnet S, Rousseau E, Marthan R, Savineau JP: Sildenafil alters calcium signaling and vascular tone in pulmonary arteries from chronically hypoxic rats. Am J Physiol Lung Cell Mol Physiol 2004, 287:L577-83.

31. Lovren F, Triggle C: Nitric oxide and sodium nitroprussideinduced relaxation of the human umbilical artery. $\mathrm{Br}$ J Pharmacol 2000, | 3 |:52 |-529.

32. Kondo U, Kim SO, Murray PA: Propofol selectively attenuates endothelium-dependent pulmonary vasodilation in chronically instrumented dogs. Anesthesiology 2000, 93:437-446.

33. Tanaka S, Kanaya N, Homma Y, Damron DS, Murray PA: Propofol increases pulmonary artery smooth muscle myofilament calcium sensitivity: role of protein kinase C. Anesthesiology 2002, 97:1557-1566.

34. Ogawa K, Tanaka S, Murray PA: Inhibitory effects of etomidate and ketamine on endothelium-dependent relaxation in canine pulmonary artery. Anesthesiology 2001, 94:668-677.

35. Hopkins N, McLoughlin P: The structural basis of pulmonary hypertension in chronic lung disease: remodelling, rarefaction or angiogenesis? J Anat 2002, 201:335-348.

36. Welsh DJ, Peacock AJ, MacLean M, Harnett M: Chronic hypoxia induces constitutive p38 mitogen-activated protein kinase activity that correlates with enhanced cellular proliferation in fibroblasts from rat pulmonary but not systemic arteries. Am J Respir Crit Care Med 200I, I 64:282-289.

37. Hamada H, Damron DS, Murray PA: Intravenous anesthetics attenuate phenylephrine-induced calcium oscillations in individual pulmonary artery smooth muscle cells. Anesthesiology 1997, 87:900-907.

38. Gelissen HP, Epema AH, Henning RH, Krijnen HJ, Hennis PJ, den Hertog A: Inotropic effects of propofol, thiopental, midazolam, etomidate, and ketamine on isolated human atrial muscle. Anesthesiology 1996, 84:397-403.

39. Esener Z, Sarihasan B, Guven H, Ustun E: Thiopentone and etomidate concentrations in maternal and umbilical plasma, and in colostrum. $\mathrm{Br}$ J Anaesth 1992, 69:586-588.

40. Shafer A, Doze VA, Shafer SL, White PF: Pharmacokinetics and pharmacodynamics of propofol infusions during general anesthesia. Anesthesiology 1988, 69:348-356.

4I. Doenicke A, Loffler B, Kugler J, Suttmann H, Grote B: Plasma concentration and E.E.G. after various regimens of etomidate. Br J Anaesth 1982, 54:393-400.

42. Belouchi NE, Roux E, Savineau JP, Marthan R: Interaction of extracellular albumin and intravenous anaesthetics, etomidate and propofol, on calcium signalling in rat airway smooth muscle cells. Fundam Clin Pharmacol 2000, I 4:395-400.

\section{Pre-publication history}

The pre-publication history for this paper can be accessed here:

http://www.biomedcentral.com/1471-2253/6/2/prepub

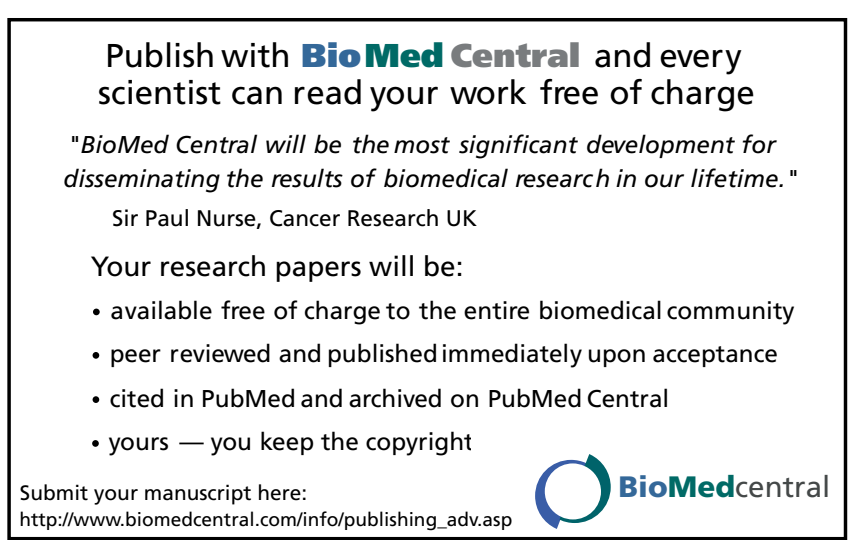

